Jurnal Riset Agama

Volume 1, Nomor 1 (April 2021): 133-144

https://journal.uinsgd.ac.id/index.php/jra

\title{
Kewajiban Menuntut Ilmu dalam Perspektif Hadis
}

\author{
Nurlia Putri Darani \\ Department of Hadith Science, Faculty of Usuluddin \\ UIN Sunan Gunung Djati Bandung \\ nurliaputri29@gmail.com
}

\begin{abstract}
The purpose of this study is to discuss how the explanation of the hadith about the obligation to study. This research method uses a qualitative type through literature study with content analysis. The results and discussion of this study include the meaning of studying, takhrij hadith about the obligation to study, and how the ethics of a student in studying. The conclusion of this study shows that the command to study is an obligation and the hadith that explains the obligation to study is a saheeh hadith. This study recommends the importance of understanding among Muslims about their obligations in studying.
\end{abstract}

Keywords: Adab, Hadith, Science

\begin{abstract}
Abstrak
Tujuan penelitian ini adalah membahas bagaimana penjelasan hadis tentang kewajiban menuntut ilmu. Metode penelitian ini menggunakan jenis kualitatif melalui studi pustaka dengan analisis isi. Hasil dan pembahasan penelitian ini meliputi makna menuntut ilmu, takhrij hadis tentang kewajiban menuntut ilmu, dan bagaimana etika seorang pelajar dalam menuntut ilmu. Kesimpulan penelitian ini menunjukan bahwa perintah menuntut ilmu adalah kewajiban dan hadis yang menjelaskan kewajiban menuntut ilmu adalah hadis yang shahih. Penelitian ini merekomendasikan pentingnya pemahaman di tengah umat muslim akan kewajibannya dalam menuntut ilmu.
\end{abstract}

Kata Kunci: Adab, Hadis, Ilmu

\section{Pendahuluan}

Menuntut ilmu adalah suatu kewajiban bagi kaum muslim dan muslimah. Dikatakan bahwa seseorang harus menuntut ilmu dari lahir sampai liang lahat. Ini membuktikan bahwa selama manusia hidup maka diharuskan untuk menuntut ilmu. Karena dengan ilmu itulah derajat seseorang akan diangkat. Namun, menuntut ilmu dibutuhkan pemahaman serta etika berdasarkan dali-dalil agama agar Allah Swt memberi kemudahan dalam 
Jurnal Riset Agama, Volume 1, Nomor 1 (April 2021): 133-144

Nurlia Putri Darani / Kewajiban Menuntut Ilmu dalam Perspektif Hadis

tujuan menuntut ilmu. Oleh karena itu, penting bagi umat muslim mempelajari dalil-dalil yang berkaitan dengan kewajiban menuntut ilmu dan memahami etika seorang pelajar dalam menuntut ilmu agar bisa memperoleh ilmu dengan maksimal (Angelia, 2017).

Sejumlah pakar telah melakukan penelitian tentang hal tersebut sebagaimana dalam tinjauan pustaka ini. Antara lain Rasyid, Abdul (2017), "Kewajiban Menuntut Ilmu," Jurnal Waraqat STAI As-Sunnah. Artikel ini menjelaskan bahwa ilmu adalah sesuatu yang sangat penting. Bahkan agama Islam tidak akan bisa tegak kecuali dengan ilmu (Rasyid, 2017). Syahril (2017), "Motivasi Belajar dalam Perspektif Hadits," Jurnal At-Taujih Universitas Islam Negeri Imam Bonjol Padang. Artikel ini membahas hadits tentang kewajiban menuntut ilmu baik secara implisit maupun eksplisit. Artikel ini juga menjelaskan perbedaan motivasi belajar menurut teori Islam dan teori Barat. Hasil dari pembahasan artikel ini untuk membentuk pemikiran bahwa belajar itu bukan hanya untuk kepentingan dunia saja, tapi juga kehidupan akhirat (Syahril, 2017). Fattah, Abdul. \& Afwadzi, Benny2016), "Pemahaman Hadits Tarbawi Burhan Al-Islam Al-Zarnuji dalam kitab Ta'lim al Muta'allim," Penerbit Universitas Islam Negeri Maulana Malik Ibrahim Malang. Artikel ini membedah pemahaman Imam Al-Zarnuji tentang hadits tarbawi dalam kitabnya yang fenomenal yaitu Ta'lim al Muta'allim (Fattah, 2016).

Berbagai penelitian terdahulu berharga bagi penyusunan kerangka berpikir penelitian ini. Menuntut ilmu merupakan sebuah keharusan bagi setiap muslim dan muslimah (Angelia, 2017). Menuntut ilmu adalah kewajiban setiap manusia yang telah dimulai sejak dilahirkan hingga ke liang lahat (Pinayungan, 2020). Mencari ilmu tidak semudah menikmati hasil, dibalik kesuksesan tentu ada perjuangan besar, dalam mencari ilmu akan ditemukan banyak rintangan, baik berupa ekonomi ataupun jiwa sendiri, mulai dari waktu, biaya, kesehatan dan kecerdasan serta keikhlasan. Orang yang ikhlas dalam menuntut ilmu akan Allah mudahkan ia dalam perjalanannya, rintangan yang ada bukanlah hambatan untuk melangkah pergi mencari ilmu (Angelia, 2017). Rasulullah saw. bersabda: “Menuntut ilmu wajib atas setiap muslim" (Angelia, 2017). "Carilah ilmu dari buaian ibu (lahir) sampai liang lahat (wafat)" HR. Ahmad (Saihu, 2020). Rasulullah shallallahu 'alaihi wasallam bersabda: "Barangsiapa keluar dalam rangka menuntut ilmu maka dia berada di jalan Allah sampai dia kembali (Angelia, 2017). Disebutkan bahwa salah satu etika dalam menuntut ilmu adalah menerima ilmu secara lisan dan bertemu langsung dengan para guru, duduk bersama para syaikh dan mengambil langsung dari lisan-lisan perawi. Bukan dari lembaranlembaran dan halaman-halaman kitab (Pinayungan, 2020). Kesungguhan 
belajar ditunjukkan dari bagaimana penuntut ilmu mengulang kembali apa yang sudah dipelajari agar melekat dalam ingatan (Pinayungan, 2020). Hendaknya seseorang penuntut ilmu membersihkan hatinya dari segala kecurangan, kotoran, iri, dengki, keyakinan yang buruk, dan akhlak yang jelek (Pinayungan, 2020).

Berdasarkan paparan di atas, formula penelitian disusun, yaitu rumusan masalah penelitian, pertanyaan utama penelitian, dan tujuan penelitian (Darmalaksana, 2020). Rumusan masalah penelitian ini adalah terdapat penjelasan hadis tentang kewajiban menuntut ilmu. Pertanyaan utama penelitian ini adalah bagaimana penjelasan hadis tentang kewajiban menuntut ilmu. Sedangkan pertanyaan secara terperinci yaitu bagaimana makna menuntut ilmu, bagaimana hadis tentang menuntut ilmu, dan bagaimana etika seorang pelajar dalam menuntut ilmu. Tujuan penelitian ini adalah membahas penjelasan hadis tentang kewajiban menuntut ilmu. Penelitian ini diharapkan bermanfaat bagi pengayaan khazanah pengetahuan Islam.

\section{Metode Penelitian}

Penelitian ini menggunakan jenis kualitatif melalui studi pustaka dengan analisis isi (Darmalaksana, 2020).

\section{Hasil dan Pembahasan Penelitian}

Hasil dan pembahasan penelitian di bawah ini.

\section{Pandangan Umum Kewajiban Menuntut Ilmu}

Ilmu dalam pandangan Islam ialah suatu proses representasi yang dapat memaparkan objek dengan jelas yang di dalamnya tidak mengandung keraguan dan kemungkinan yang keliru, tetapi berisi kebenaran yang kuat (Toha, 1996). Djamaluddin Darwis dalam bukunya yang berjudul, "Dinamika Pendidikan Islam" menyebutkan bahwa mencari ilmu itu adalah sebuah kewajiban dan sekaligus kebutuhan umat manusia. Manusia akan lebih mudah menjalani dan memenuhi kebutuhan hidup jika terdidik. Belajar dimaknai sebagai proses pendewasaan untuk mewujudkan kehidupan yang lebih maju dan sejahtera lahir dan batin (Darwis, 2006). Islam mewajibkan umatnya untuk menuntut ilmu, karena ilmu menjadi sarana terbaik untuk mencerdaskan umat dan membangun peradaban dunia, khususnya bila ilmu ini diterapkan dalam kehidupan sehari-hari. Wahyu yang pertama kali diturunkan sangat berkaitan dengan perintah menuntut ilmu. "Bacalah dengan (menyebut) nama Tuhanmu yang menciptakan, Dia telah menciptakan manusia dari segumpal darah, Bacalah, dan Tuhanmulah Yang Mahamulia, 
Yang mengajar (manusia) dengan pena, Dia mengajarkan manusia apa yang tidak diketahuinya" (QS. Al-Alaq : 1-5). Dalam ayat tersebut, perintah membaca diulangi sebanyak dua kali. Perintah yang pertama ditunjukkan kepada Rasulullah, dan selanjutnya ditunjukkan kepada seluruh umatnya. Lima ayat pertama dalam surah Al-Alaq ini menjelaskan bahwa Rasulullah diutus ke dunia untuk mengajak manusia beribadah kepada Allah dan mengembangkan ilmu pengetahuan. Dan sumber dari segala ilmu pengetahuan bisa didapatkan dari Al-Quran, baik yang menyangkut dunia maupun akhirat (Mahali, 2002). Perintah membaca dimaksudkan agar manusia lebih banyak membaca, menelaah, memperhatikan alam semesta untuk kemudian menjadi bekal ketika turun ke masyarakat (Hasani, 2017).

Pentingnya manusia menuntut ilmu bukan hanya untuk membantu mendapatkan kehidupan yang layak, tetapi dengan ilmu manusia akan mampu mengenal tuhannya, memperbaiki akhlaknya, juga senantiasa mencari keridhaan Allah (Pinayungan, 2020). Menuntut ilmu adalah ibadah yang paling afdhol. Karena semua ibadah tidak bisa ditunaikan sesuai dengan ketentuan yang Allah dan Rasul-Nya kecuali dengan ilmu. Maka perlu diketahui bahwa ibadah adalah tanggung jawab manusia yang selalu melekat selama masih bernafas di dunia. Artinya, ibadah menuntut ilmu ini adalah aktifitas yang tidak berujung, kecuali satu, yaitu kematian. Menuntut ilmu merupakan kewajiban bagi setiap muslim. Dengan iman dan ilmu maka Allah akan meninggikann derajat seorang muslim. Sebagaimana firman-Nya: "Dan apabila dikatakan: 'Berdirilah kamu', Maka berdirilah, niscaya Allah akan meninggikan orang-orang yang beriman di antaramu dan orang-orang yang diberi ilmu pengetahuan beberapa derajat. dan Allah Maha mengetahui apa yang kamu kerjakan" (QS. Al-Mujadallah : 11). Islam memandang pendidikan adalah hak setiap manusia (education for all) baik laki-laki atau perempuan dan berlangsung sepanjang hayat (long life education). Kehidupan dunia tidak akan sepi dari proses belajar, sejak mulai manusia dilahirkan sampai menemui kematian. Islam telah merencanakan pendidikan manusia dalam Al-Quran seperti siapa manusia, dari mana manusia, dan mau ke mana manusia juga harus bagaimana manusia hidup di dunia. Pertanyaan seperti itu yang akan mengarahkan manusia mencari tujuannya sebagai manusia dengan terus belajar sepanjang hayat (Wahyudin, 2017). Ada lebih dari satu hadis yang menjelaskan pentingnya menuntut ilmu. Hadis-hadis tersebut mengisyaratkan bahwa belajar atau menuntut ilmu adalah suatu aktifitas yang dilakukan sepanjang usia, tidak mengenal umur, jenis kelamin, jarak, ataupun keadaan geografis. Semenjak ikrar primordial berupa kesaksian terhadap 
ketuhanan yang satu dan kenabian Muhammad dikumandangkan, maka kewajiban itu melekat pada diri manusia (Hanafi, 2020).

Perjuangan dalam menuntut ilmu bisa terlihat dari kesungguhan para sahabat dalam mencari ilmu, para sahabat yang berasal dari daerah yang berbeda dengan Rasulullah, yang berjauh-jauh milnya, tetap semangat bertemu dengan Rasulullah, mereka rela melakukan perjalanan yang jauh demi bisa berguru langsung kepada Rasulullah. Begitupun pada kondisi para tabiin dan tabi' tabiin, berkelana ke berbagai wilayah untuk mencari hadishadis Rasulullah. Imam Bukhori misalnya, seorang ahli hadis yang paling masyhur di antara Imam Muslim, Abu Daud, Tirmidzi, dan An-Nasai yang melakukan perjalanan selama 16 tahun dalam mengumpulkan hadis. Penulis kitab Shohih Bukhori ini berkelana ke berbagai tempat mulai dari Makkah, Madinah, Khurasan, Basrah, Baghdad, Syam, Mesir dan wilayah lainnya (Zarman, 2012). Dikisahkan tata cara belajar imam Syafi'i, "Setelah aku hafal Al-Quran, aku masuk ke Masjidil Haram untuk berguru kepada para ulama. Dari merekalah aku menimba ilmu, menghafal hadis, dan berbagai masalah ilmiah lainnya. Rumahku berada di lereng bukit Khaif. Aku sering melihat potongan tulang yang putih berkilauan, kemudian tulang itu kupungut dan kujadikan sarana menulis hadits atau masalah ilmiah lainnya. Dahulu kami memiliki sebuah guci tua untuk menyimpan potongan-potongan tulang itu. Tiap kali tulang yang aku bawa telah penuh berisi tulisan, aku menyimpannya dalam guci itu." Bahkan untuk mempelajari bahasa Arab saja, Imam Syafi'i berkenala di pedusunan Arab Badui selama dua puluh tahun. Ia ikut kabilah Hudzail karena bahasa mereka paling fasih. Imam Syafi'i mengikuti kemanapun kabilah itu pergi, karena pada saat itu banyak kabilah-kabilah Arab yang hidup nomaden (Ridwan, 2016). Perjuangan mencari ilmu tidak semudah ketika menikmati hasil, pasti akan ada perjuangan yang besar untuk menikmati hasil yang didambakan. Dalam mencari ilmu akan ditemukan banyak sekali rintangan yang siap menghadang, baik dari segi ekonomi, waktu, jiwa, kesehatan, serta keikhlasan. Orang yang ikhlas dalam menuntut ilmu akan Allah mudahkan dalam perjalanan mencari ilmu, dan rintangan yang ada seharusnya bukan hambatan untuk melangkahkan kaki pergi mencari ilmu (Umar, 2014).

\section{Takhrij Hadis tentang Kewajiban Menuntut Ilmu}

Pada pembahasan kali ini, kegiatan takhrij menggunakan program Mausu'ah al-Hadis al-Syarif al-Kutub al-Tis'ah yang di dalamnya mencakup Kutub al-Tis'ah (Shahih al-Bukhari, Shahih Muslim, Sunan al-Tirmizi, Sunan alNasa'i, Sunan Abu Dawud, Sunan Ibn Majah, Musnad Ahmad Ibn Hanbal, Muwatta' 
Jurnal Riset Agama, Volume 1, Nomor 1 (April 2021): 133-144

Nurlia Putri Darani / Kewajiban Menuntut Ilmu dalam Perspektif Hadis

Malik, dan Sunan al-Darimi). Hadis yang akan ditakhrij adalah hadis yang terdapat dalam kitab Sunan Ibnu Majah dengan ranngkaian sanad dan matan sebagai berikut:

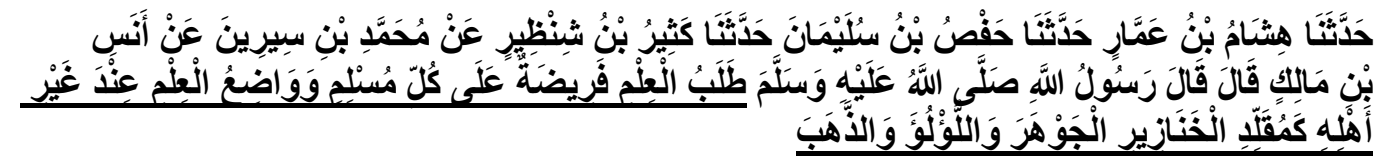

Telah menceritakan kepada kami Hisyam bin Ammar berkata, telah menceritakan kepada kami Hafsh bin Sulaiman berkata, telah menceritakan kepada kami Katsir bin Syinzhir dari Muhammad bin Sirin dari Anas bin Malik ia berkata; Rasulullah shallallahu 'alaihi wasallam bersabda: "Menuntut ilmu adalah kewajiban bagi setiap muslim. Dan orang yang meletakkan ilmu bukan pada pada ahlinya, seperti seorang yang mengalungkan mutiara, intan dan emas ke leher babi" (HR. Ibnu Majah).

Dari hasil pencarian ditemukan bahwa hadis di atas tidak hanya ditemukan dalam Sunan Ibnu Majah saja, melainkan terdapat juga dalam beberapa kitab hadis lainnya di antaranya:

Tabel 1 Daftar Hadis

\begin{tabular}{|c|l|l|c|c|}
\hline No & Mukharrij & Nama Kitab & Juz & Jumlah Hadis \\
\hline 1 & Al-Thabrani & Al-Mu'jam al-Shagir & 1 & 2 Hadis \\
\hline 2 & Al-Thabarani & Al-Mu'jam al-Aswath & $1-8$ & 9 Hadis \\
\hline 3 & Al-Thabarani & Al-Mu'jam al-Kabir & 9,10 & 2 Hadis \\
\hline 4 & Al-Baihaqi & Sya'ab al-Iman & 3 & 15 Hadis \\
\hline 5 & Al-Ashbahani & Hilyah al-Auliya' & 8,10 & 2 Hadis \\
\hline 6 & Abi Ya'la & Musnad Abi Ya'la & 5,7 & 3 Hadis \\
\hline 7 & Al-Bazzar & Musnad al-Bazzar & 1,2 & 6 Hadis \\
\hline 8 & Al-Thabarani & Musnad al-Syamiyyin & 3,4 & 2 Hadis \\
\hline 9 & Al-Qadha'i & Musnad al-Syahab & 1 & 3 Hadis \\
\hline
\end{tabular}

Tahkrij pada hadis yang telah disebutkan sebelumnya akan diteliti pada segi matan. Penetapan tolak ukur matan bisa dipastikan dengan empat macam yakni; 1) kajian linguistik, 2) tidak bertentangan dengan Al-Quran, 3) tidak bertentangan dengan hadis yang lebih kuat, dan 4) tidak bertentangan dengan akal sehat (Shalahudin, 1983).

\section{1) Kajian Linguistik}




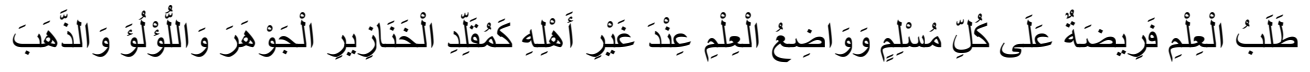

Artinya: "Menuntut ilmu adalah kewajiban bagi setiap muslim. Dan orang yang meletakkan ilmu bukan pada pada ahlinya, seperti seorang yang mengalungkan mutiara, intan dan emas ke leher babi" (HR. Ibnu Majah).

Kata طَلَ mengandung makna menuntut atau mencari sesuatu, maksudnya ilmu itu diperoleh dengan mencari bukan berandai-andai. Kata

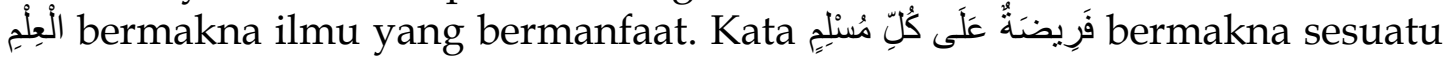
hal yang harus dilakukan oleh kaum muslim dan muslimah. Juga pada kata

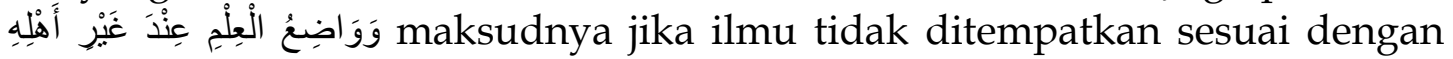
tempatnya maka ilmu tersebut tidak akan membawa manfaat. Sedangkan kata

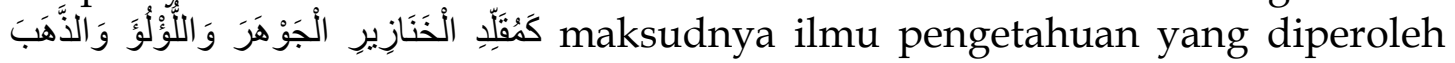
tidak akan bermanfaat.

\section{2) Tidak Bertentangan dengan Petunjuk Al-Quran}

Kewajiban menuntu ilmu ada dalah Qs. At-Taubah : 122 yang berbunyi:

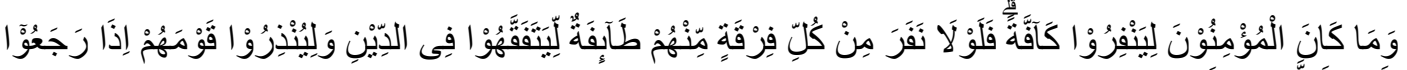

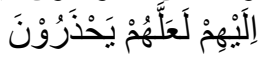

"Dan tidak sepatutnya orang-orang mukmin itu semuanya pergi (ke medan perang). Mengapa sebagian dari setiap golongan di antara mereka tidak pergi untuk memperdalam pengetahuan agama mereka dan untuk memberi peringatan kepada kaumnya apabila mereka telah kembali, agar mereka dapat menjaga dirinya" (QS. At-Taubah : 122).

Walaupun dalam ayat di atas tidak ada kata-kata wajibun atau faridhatun yang bermakna keharusan, tetapi dalam ayat di atas terdapat lafadz liyatafaqqahuu yang merupakan fi'il mudhari yang dimasukan lamul amr. Dalam kaidah Ushul Fiqh dikatakan, "Arti yang pokok dalam amr ialah menunjukkan wajib." Maka ayat di atas memiliki arti bahwa menuntut ilmu itu wajib (Alimron, 2015).

\section{3) Tidak Bertentangan dengan Hadis yang Lebih Kuat dan Sirah Nabi}

Hadis tentang kewajiban menuntut ilmu tidak bertentangan dengan hadis yang lebih kuat. Hadis kewajiban menuntut ilmu selain diriwayatkan oleh Anas bin Malik, juga diriwayatkan oleh Ali bin Abi Thalib, Abu Sa'id AlKhudri dan Abdullah bin Mas'ud. 
Jurnal Riset Agama, Volume 1, Nomor 1 (April 2021): 133-144

Nurlia Putri Darani / Kewajiban Menuntut Ilmu dalam Perspektif Hadis

\section{4) Tidak Bertentangan dengan Akal Sehat, Indera dan Fakta Sejarah}

Manusia di beri akal oleh Allah untuk mengisi akalnya dengan ilmu pengetahuan. Juga tidak bertentangan dengan fakta sejarah menilai banyak sahabat dan para pendahulu yang rela meninggalkan kampung halamannya untuk mencari ilmu (Ridwan, 2016).

Maka dari segi analisis matan, hadis tentang kewajiban menuntut ilmu adalah Shahih. Karena memenuhi tolak ukur yang empat tadi. Oleh karena itu diharuskan kaum muslim untuk mengisi akal mereka dengan ilmu yang bermanfaat.

\section{Bagaimana Etika Seorang Pelajar dalam Menuntut Ilmu}

Menuntut ilmu tidak dilakukan sembarangan, ada adab atau etika yang mesti diketahui oleh para pelajar agar ilmu yang didapat bermanfaat dan membawa banyak berkah. Umat Islam bisa mencontoh bagaimana para ulama terdahulu mencari ilmu sehingga kemanfaatan ilmunya bisa dirasakan hingga saat ini. Hal yang diperhatikan para ulama dalam menuntut ilmu adalah memilih guru yang tepat (Ridwan, 2016). Belajar yang baik juga harus langsung mendengar dan duduk bersama sang guru. Menerima ilmu secara lisan dan bertemu langsung dengan para guru, duduk bersama para syaikh dan mengambil langsung dari lisan-lisan perawi. Bukan dari lembaranlembaran dan halaman-halaman kitab (Pinayungan, 2020). dengan berguru langsung atau yang sering disebut dengan talaqqi memudahkan para pelajar mengambil nasab ilmu dari pembawa nasab ilmu yang berakal yakni sang guru. Sedangkan jika belajar sendiri dari lembaran kitab maka tidak akan mungkin terjalin nasab keilmuan antara guru dan murid. Imam Ahmad bin Hambal ketika usianya masih remaja, imam Ahmad telah fokus mempelajari hadis. Guru pertamanya adalah Hasyim ibn Khazin Al-Wasiti. Kegigihannya dalam mengumpulkan hadis membawanya mendatangi pusat-pusat keislaman seperti Basrah, Hijaz, Yaman, Makkah, dan Kuffah. Dalam perjalanan itu beliau bertemu dengan ulama-ulama besar seperti 'Abd ArRazaq ibn Humam, 'Ali ibn Mujahid, Jarir ibn 'Abd Al-Hamid, Sufyan ibn 'Uyainah, Abu Yususf Ya'kub ibn Ibrahim Al-Ansari (murid Imam Abu Hanifah), Imam Syafi'i dan lain-lain. Pertemuan Imam Ahmad dan Imam Syafi'i membuat Imam Ahmad mempelajari fiqh, Ushul fiqh, nasikh dan mansukh juga keshahihan hadis (Al-Muhsin, 1980). Perjuangan Imam Ahmad dalam menghimpun hadis membuahkan hasil yang memuaskan juga memberi warna baru dalam pandangan fiqhnya. Karya Imam Ahmad yang paling terkenal dan masih sering digunakan hingga sekarang adalah Musnad Ahmad. Di dalamnya terdapat 40.000 hadis, ada yang berpendapat bahwa 
semua hadis dalam kitab itu statusnya shahih, tapi sebagian juga berpendapat beberapa hadis di dalamnya ada yang berstatus dha'if (Mun'im, 1995).

Seorang pelajar tidak hanya mengandalkan kecerdasannya dalam menghapal materi yang telah guru sampaikan, tetapi juga harus dicatat. Kesungguhan belajar ditunjukkan dari bagaimana penuntut ilmu mengulang kembali apa yang sudah dipelajari agar melekat dalam ingatan (Pinayungan, 2020). Ini yang dilakukan oleh para imam mazhab terdahulu ketika mencari ilmu, bukan hanya mengandalkan hapalannya tapi juga mencatat seluruh ilmu yang gurunya sampaikan di berbagai majelis ta'lim yang mereka datangi. Sebab jika seseorang hanya mengandalkan daya ingatnya saja, perlu diingat bahwa daya ingat seseorang itu terbatas, berjalannya waktu hapalannya akan sedikit demi sedikit hilang dalam ingatan, mengandalkan hafalan, pemahaman dan daya ingat dalam mencari ilmu merupakan salah satu pemahaman yang keliru, karena keraguan bisa menyusup kapan saja dan sifat lupa bisa datang secara tiba-tiba. Maka penting untuk membuat catatan. Anas bin Malik pernah meriwayatkan bahwa Rasulullah pernah bersabda "ikatlah ilmu dengan buku." Suatu ketika seorang laki-laki mengadu kepada Rasulullah tentang sifat-sifat lupanya lalu Nabi berkata "Gunakanlah tanganmu (maksudnya tulislah) sehingga ketika lupa, engkau dapat merujuk pada apa yang telah engkau tulis." Dengan hadis tersebut maka bisa diambil pelajaran bahwa Rasulullah menghendaki umatnya ketika belajar maka disarankan untuk mencatatnya. Prinsip yang dinasehatkan oleh Imam Syafi'i untuk para penuntut ilmu adalah sabar karena memerlukan waktu lama. Para penuntut ilmu harus menyiapkan diri menghabiskan waktu yang lama untuk mencapai pemahaman terhadap ilmu. Penuntut ilmu harus mempunyai rasa sabar dan ketekunan, pengetahuan dapat diperoleh dengan cepat tapi pemahaman yang matang dan mendalam hanya bisa diraih dengan kesabaran dan kesungguhan (Syarafuddin, 2015). Para penuntut ilmu bisa mencontoh Imam Syafi'i dalam membagi waktu. Imam Syafi' i membagi waktu malamnya menjadi tiga bagian, sepertiga malam pertama untuk menulis, sepertiga malam kedua untuk shalat, dan sepertiga malam terakhir untuk tidur. Ini nasehat Imam Syafi'i untuk para penuntut ilmu agar tidak membuang-buang waktunya untuk hal yang sia-sia (Sawitri, 2019).

Hal yang tidak kalah penting untuk diperhatikan para penuntut ilmu adalah niat. Kebersihan hati ketika menuntut ilmu menjadi penentu usaha dalam menuntut ilmu dinilai ibadah atau tidak. Karena niat merupakan syarat yang mutlak diterima suatu amal perbuatan. Konsep ini sangat dipahami oleh para imam madzhab dalam menuntut ilmu. Bagi mereka niat yang paling utama dalam belajar adlah mencari ridho Allah dan menghilangkan 
kebodohan. Tidak ada niat untuk memperoleh jabatan, kemasyhuran, ataupun kekayaan, segala sesuatu yang bersifat duniawi menurut para imam madzhab tidaklah berarti (Ridwan, 2016). Sesungguhnya amal itu tergantung niat seperti dalam hadis berikut:

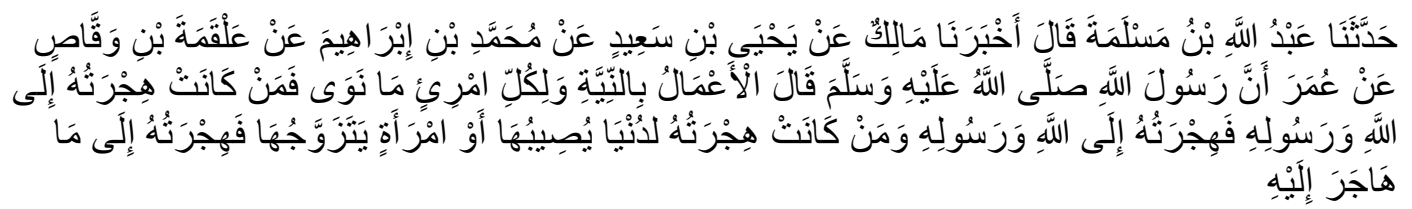

Telah menceritakan kepada kami Abdullah bin Maslamah berkata, telah mengabarkan kepada kami Malik dari Yahya bin Sa'id dari Muhammad bin Ibrahim dari Alqamah bin Waqash dari Umar, bahwa Rasulullah shallallahu 'alaihi wasallam bersabda: "Semua perbuatan tergantung niatnya, dan (balasan) bagi tiap-tiap orang (tergantung) apa yang diniatkan; barangsiapa niat hijrahnya karena Allah dan Rasul-Nya, maka hijrahnya adalah kepada Allah dan Rasul-Nya. Barangsiapa niat hijrahnya karena dunia yang ingin digapainya atau karena seorang perempuan yang ingin dinikahinya, maka hijrahnya adalah kepada apa dia diniatkan" (HR. Bukhari No. 52).

Hadis ini menjelaskan bahwa setiap amal tergantung niatnya. Dan setiap orang pasti mendapatkan balasan dari apa yang ia niatkan. Seseoranng akan mendapatkan balasan yang mulia ketika berniat ikhlas karena Allah, berbeda dengan seseorang yang berniat beramal hanya karena mengejar dunia (Hanafi, 2020).

\section{Kesimpulan}

Menuntut ilmu adalah kewajiban setiap muslim juga merupakan ibadah yang paling afdhol. Menuntut ilmu merupakan aktifitas yang tidak berujung. Islam memandang pendidikan adalah hak setiap manusia (education for all) baik laki-laki atau perempuan dan berlangsung sepanjang hayat (long life education). Akan tetapi, perjuangan menuntut ilmu itu tidak mudah, akan ditemukan banyak sekali rintangan yang siap menghadang, baik dari segi ekonomi, waktu, jiwa, kesehatan, serta keikhlasan. Tetapi jika dilakukan dengan ikhlas maka segala rintangan tidak akan menjadikan hambatan untuk melangkahkan kaki dalam mencari ilmu. Juga Allah akan memudahkan dalam perjalanan menuntut ilmu. Hadis-hadis yang menjelaskan kewajiban menuntut ilmu terdapat di berbagai kitab-kitab para ulama, juga tidak sedikit yang status hadisnya adalah shahih. Karena, hadisnya tidak bertentangan dengan Al-Quran, hadis-hadis yang lebih kuat, juga fakta sejarah yang terjadi sebelumnya. Namun, perintah menuntut ilmu juga tidak terlepas dari etika 
Jurnal Riset Agama, Volume 1, Nomor 1 (April 2021): 133-144

Nurlia Putri Darani / Kewajiban Menuntut Ilmu dalam Perspektif Hadis

atau adab yang harus para pelajar perhatikan agar ilmu yang didapat bukan sekedar hanya informasi semata tetapi bermanfaat juga untuk masyarakat dan bernilai pahala. Diharapkan penelitian ini membawa manfaat agar kaum muslim lebih sadar akan pentingnya menuntut ilmu. Penelitian ini tentunya memiliki keterbatasan dalam beberapa hal. Sehingga dibutuhkan penelitian lanjutan, khususnya dalam bidang takhrij hadis tentang perintah menuntut ilmu.

\section{Daftar Pustaka}

Alimron. (2015). Studi Validitas Hadis Tentang Ilmu Pengetahuan Dalam Buku Pendidikan Agama Islam Dan Budi Pekerti Kurikulum 2013. Tadrib : Jurnal Raden Fatah , 9.

Al-Muhsin, A. i. (1980). Ushul Mazhab al-Imam Ahmad. Riyad: Maktabah ArRiyad Al-Hadisah.

Angelia, Y. H. (2017). Merantau dalam Menuntut Ilmu . UIN Sunan Kalijaga, 1. Darmalaksana, W. (2020). Formula Penelitian Pengalaman Kelas Menulis. Kelas Menulis UIN Sunan Gunung Djati Bandung, 1-8.

Darmalaksana, W. (2020). Metode Penelitian Kualitatif Studi Pustaka dan Studi Lapangan. UIN Sunan Gunung Djati Bandung, 1-3.

Darwis, D. (2006). Dinamika Pendidikan Islam . Semarang : Rasail.

Fattah, A. \&. (2016). Pemahaman Hadits Tarbawi Burhan Al-Islam Al-Zarnuji dalam kitab Ta'lim al Muta'allim. Universitas Islam Negeri Maulana Malik Ibrahim Malang .

Hanafi, A. (2020). Memaknai Aktifitas Belajar Sebagai Ibadah Dengan Kontekstualisasi Pemahaman Hadis Innamal A'malu Bin Niyat . Misykah : Jurnal Pemikiran dan Studi Islam , 154.

Hasani, M. (2017). Urgensi Belajar dalam Surat Al-Alaq Ayat 1-5. UIN Sultan Maulana Hasanuddin Banten , 105.

Mahali, M. (2002). Asbabun Nuzul Studi Pendalaman Al-Qur'an . Jakarta : Raja Grapindo Persada .

Mun'im, A. S. (1995). Sejarah Figh ISlam. Surabaya: Risalah Gusti.

Pinayungan, T. (2020). konsep Menuntut Ilmu Menurut Ust Adi Hidayat. IAIN Purwokerto, 1.

Rasyid, A. (2017). Kewajiban Menuntut Ilmu,. Jurnal Waraqat STAI As-Sunnah. Ridwan, M. (2016). Menilik Rahasia Belajar Imam Madzhab . Misykah : Jurnal Pemikiran dan Studi Islam , 209.

Saihu. (2020). Etika Menuntut Ilmu Menurut Kitab Ta'lim Muta'allim. Al Amin: Jurnal kajian ilmu dan Kajian Islam, 101. 
Jurnal Riset Agama, Volume 1, Nomor 1 (April 2021): 133-144

Nurlia Putri Darani / Kewajiban Menuntut Ilmu dalam Perspektif Hadis

Sawitri, V. F. (2019). Konsep Sabar Dalam Menuntut Ilmu Pada Kitab Diwan Al-Imam Asy-Syafi'i. IAIN Salatiga , 72.

Shalahudin, M. (1983). Al-Adlabi, Manhaj Naqd al-Matn. Beirut: Dar al-Afaq alJadidah.

Syahril. (2017). Motivasi Belajar dalam Perspektif Hadits . At-taujih Universitas Islam Negeri Imam Bonjol Padang .

Syarafuddin, C. W. (2015). Peningkatan Kontribusi Manajemen Pendidikan dalam Pengembangan Sumber Daya Manusia Berkualitas untuk. Medan: Perdana Publishing.

Toha, C. (1996). Kapita Selekta Pendidikan Islam. Yogyakarta : 1996.

Umar, B. (2014). Hadis Tarbawi Pendidikan Dalam Perspektif Hadis. Jakarta: AMZAH.

Wahyudin, W. (2017). Pendidikan Sepanjang Hayat Menurut Perspektif Islam (Kajian Tafsir Tarbawi). Saintifika Islamica Jurnal Kajian Keislaman, 202203.

Zarman, W. (2012). Inilah! Wasiat Nabi bagi Para Penuntut Ilmu . Jakarta: Ruang Kata Imprint Kawan Pustaka. 